ISSN 1981-416X

Licenciado sob uma Licença Creative Commons

\title{
Educação a distância e inclusão: uma análise sob a perspectiva docente ${ }^{1}$
}

\author{
Distance education and inclusion: an analysis from the \\ perspective of teachers
}

\section{Educación a distancia e inclusión: un análisis de la perspectiva de los profesores}

\section{Braian Garrito Veloso, Daniel Mill*}

\section{Resumo}

O objetivo principal desta pesquisa é discutir, sob a perspectiva docente, a inclusão possibilitada pela Educação a Distância (EaD). A investigação foi empreendida no âmbito do Sistema Universidade Aberta do Brasil (UAB). No que concerne aos procedimentos metodológicos, foram coletados, por meio de questionários virtuais, dados de 677 docentes que atuam ou já atuaram em cursos oferecidos no âmbito do Sistema UAB. Após isso, foram realizadas 8 entrevistas semiestruturadas. Concomitantemente, coletou-se dados em fontes documentais, quais sejam, processos seletivos, documentos oficiais, editais e

\footnotetext{
${ }^{1}$ Pesquisa realizada com apoio financeiro da Coordenação de Aperfeiçoamento de Pessoal de Nível Superior (CAPES).
}

"BGV: Mestre em Educação, e-mail: braiangarritoveloso@gmail.com DM: Doutor em Educação, e-mail: mill@ead.ufscar.br 
outras informações disponibilizadas virtualmente nas páginas das instituições públicas que ofertam cursos a distância. Por sua vez, os dados foram submetidos a uma análise quantitativa e qualitativa. Com o estudo, identifica-se que a EaD está relacionada a processos inclusivos. A flexibilidade nos editais de contratação permite que professores da educação básica encontrem no Sistema UAB a oportunidade para atuar no ensino superior. Ademais, a disparidade temporal e espacial, bem como o teletrabalho, possibilitam que os docentes consigam sobrepujar diferentes problemáticas, como distância geográfica, problemas de saúde, situações de opressão, descaso do Estado, etc.

Palavras-chave: Educação a Distância. Trabalho Docente. Inclusão.

\section{Abstract}

The main objective of this research is to discuss, from a teaching perspective, the inclusion made possible by distance education. The research was done under the Universidade Aberta do Brasil (UAB) system. Regarding the methodological procedures, data were collected through virtual questionnaires of 677 teachers who work or have already worked in courses offered under the UAB System. After that, 8 semi-structured interviews were carried out. At the same time, data were collected in documentary sources, namely, selective processes, official documents, edicts and other information available virtually on the pages of public institutions that offer distance courses. In turn, the data were submitted to quantitative and qualitative analysis. With the study, it is identified that distance education is related to inclusive processes. Flexibility in contracting tutors allows primary education teachers to find in the UAB system the opportunity to work in higher education. In addition, temporal and spatial disparities, as well as teleworking, allow teachers to overcome different problems, such as geographic distance, health problems, situations of oppression, neglect of the State, etc.

Keywords: Distance Education. Teaching Work. Inclusion. 


\section{Resumen}

El objetivo principal de esta investigación es discutir, desde perspectiva del docente, la inclusión posibilitada por la Educación a Distancia (EaD). La investigación fue emprendida en el ámbito del Sistema Universidade Aberta do Brasil (UAB). En lo que concierne a los procedimientos metodológicos, fueron recogidos, por medio de cuestionarios virtuales, datos de 677 docentes que actúan o ya actuaron en cursos ofrecidos en el ámbito del Sistema UAB. Después de eso, se realizaron 8 entrevistas semiestructuradas. Concomitantemente, se recogieron datos en fuentes documentales, cuales son, procesos selectivos, documentos oficiales, edictos y otras informaciones disponibles virtualmente en las páginas de las instituciones públicas que ofrecen cursos a distancia. Por su parte, los datos se sometieron a un análisis cuantitativo y cualitativo. Con el estudio, se identifica que la EaD está relacionada con procesos inclusivos. La flexibilidad en los edictos de contratación permite que profesores de educación básica encuentren en el Sistema UAB la oportunidad para actuar en la enseñanza superior. Además, la disparidad temporal y espacial, así como el teletrabajo, posibilitan que los docentes puedan sobrepasar diferentes problemáticas, como distancia geográfica, problemas de salud, situaciones de opresión, descuido del Estado, etc.

Palabras clave: Educación a Distancia. Trabajo Docente. Inclusión.

\section{Introdução}

O principal objetivo desta pesquisa é discutir, a partir da perspectiva dos docentes, a inclusão possibilitada pela Educação a Distância (EaD). Acreditamos que a docência na modalidade, sendo flexível, promove distintas oportunidades aos profissionais. A disparidade temporal e espacial dos sujeitos envolvidos no processo de ensino-aprendizagem, por exemplo, permite que os docentes conciliem suas atividades com outras demandas pessoais. Essas características imanentes às propostas contemporâneas de EaD desvelam o caráter inclusivo dos cursos 
oferecidos a distância. Caráter este que, historicamente, mostra-se indissociável da modalidade.

Concernentemente aos procedimentos metodológicos, ressalta-se que esta investigação foi realizada no âmbito do Sistema Universidade Aberta do Brasil (UAB). Trata-se de uma das políticas públicas de maior importância no que tange à expansão da EaD no País. Dessa maneira, foram aplicados questionários virtuais a exatamente 677 docentes que atuam ou já atuaram em cursos oferecidos pelo Sistema UAB. Nomeadamente, participaram da pesquisa docentes-formadores/ aplicadores, docentes-autores/conteudistas e docentes-tutores (virtuais e presenciais). Após a aplicação dos questionários, foram realizadas entrevistas com 8 desses profissionais. Os dados foram submetidos a uma análise quantitativa e qualitativa.

No que diz respeito à estrutura do texto, primeiramente são apresentados alguns fundamentos teóricos relacionando EaD e inclusão. Em seguida, encontram-se a metodologia e os procedimentos metodológicos. Posteriormente, discute-se os dados coletados para, por fim, serem estabelecidas algumas considerações finais, visando contribuir para as pesquisas da área.

\section{Educação a Distância e inclusão}

Historicamente, a Educação a Distância se mostra alinhada a processos de inclusão. De acordo com Moore e Kearsley (2007), a modalidade, quando ainda utilizava da correspondência, tinha como um de seus objetivos lançar mão de tecnologias para chegar até aqueles que, de outro modo, não seriam atendidos. Na contemporaneidade, essa característica ainda se mostra fundante, posto que a EaD, "em termos gerais, permite muitas novas oportunidades de aprendizado para um grande número de pessoas" (MOORE; KEARSLEY, 2007, p. 21). Os autores ainda consideram que: 
À medida que a utilização da educação a distância se disseminar, populações anteriormente em desvantagem, como os alunos de áreas rurais ou de regiões no interior das cidades, poderão fazer cursos nas mesmas instituições e com o mesmo corpo docente que anteriormente estavam disponíveis apenas para alunos em áreas privilegiadas e residenciais de bom nível (MOORE; KEARSLEY, 2007, p. 21).

Quer dizer que a EaD permite que mais pessoas obtenham acesso a mais e melhores recursos de aprendizado do que podiam no passado, quando se limitavam àquilo que era oferecido localmente (MOORE; KEARSLEY, 2007). Seu caráter inclusivo é, assim, uma das características mais importantes da modalidade. Justamente por isso, a EaD se mostra como elemento estratégico quando da democratização e interiorização da oferta educacional. Para Sancho-Gil (2016), nos últimos anos, o desenvolvimento econômico e tecnológico, bem como a globalização, levaram muitos países a enfocar a melhoria da educação, repercutindo numa significativa abertura de universidades públicas e privadas e, especialmente, dadas as características geográficas de países como o Brasil, a organização de um bom número de programas de EaD.

Nessa ambiência, políticas públicas têm surgido com vistas a explorar a possibilidade de uma educação cujos sujeitos se encontram separados no tempo e no espaço. A título de exemplo, em 2006 foi instituído o Sistema Universidade Aberta do Brasil (UAB), com a finalidade de expandir e interiorizar a oferta de cursos e programas de educação superior no Brasil (NEVES, 2016). Este Sistema é considerado a mais evidente e vultosa política pública de educação superior a distância no País (FERREIRA; CARNEIRO, 2015). Assim, destaca-se que a instalação do Sistema UAB "foi uma das molas propulsoras da melhoria quali-quantitativa da EaD no país, pois integrou praticamente todas as instituições públicas de ensino superior brasileiras, que investiram intensamente na incorporação dessa modalidade" (MILL, 2016, p. 131).

A expansão de cursos a distância em território nacional vem acompanhada de um debate acerca da qualidade do ensino oferecido. Para além das problemáticas que permeiam o Sistema UAB, além daquelas 
atinentes aos desafios que perpassam a modalidade, há que se considerar o aspecto inclusivo dessa política pública. Instituída com o objetivo precípuo de expandir e interiorizar a oferta de educação superior no Brasil, percebe-se que o fomento da EaD está atrelado ao acesso educacional àqueles que, por outras vias, não seriam atendidos. Por conseguinte, as discussões sobre cursos oferecidos a distância se concentram, via de regra, na democratização do ensino a partir da perspectiva discente. No entanto, a possiblidade de atuar em tempos e espaços distintos também sinaliza benefícios para os profissionais docentes da EaD. Atualmente, em decorrência dos avanços das Tecnologias Digitais de Informação e Comunicação, torna-se cada vez mais acessível atuar como docente num curso ofertado a distância, possibilitando que os profissionais conciliem diversos afazeres com a docência virtual.

Como consequência da possibilidade de atuar em tempos e espaços flexíveis, o trabalho na EaD tem acolhido trabalhadores que, noutras condições, se encontrariam à margem das atividades docentes ou mesmo laborais, de uma forma geral. Noutras palavras, a atuação a distância como teletrabalho ${ }^{2}$, possibilitada pelos avanços das TDIC, faz com que os profissionais consigam conciliar o emprego com demais atividades, quer de lazer, quer de estudo, quer de convívio com a família etc. Evidentemente, existem diversas características perversas que subjazem ao trabalho flexível, nomeadamente aquele realizado em domicílio como teletrabalho. Inclusive, vários aspectos negativos já foram evidenciados noutros estudos, tais como os de Veloso (2018), Veloso e Mill (2017), Veloso e Mill (2018), dentre outros. Portanto, registramos nestas páginas que não defendemos uma concepção ingênua de que a flexibilidade da docência na EaD incorre em benefícios sem precedentes

${ }^{2}$ Grosso modo, entendemos o teletrabalho como aquele em que empregadores e empregados se encontram distantes geograficamente, mas mantêm-se conectados por meio de tecnologias diversas. $\mathrm{Na}$ forma como a EaD tem se constituído na contemporaneidade, a docência tem sido exercida preponderantemente como teletrabalho. Para conhecer mais sobre essa forma de trabalho realizado a distância e suas implicações para a atividade docente na EaD, ver Veloso e Mill (2017). 
para os trabalhadores. Pelo contrário, consideramos que o teletrabalho se relaciona com tendências do regime de acumulação flexível, colimando a exploração dos profissionais sob diferentes perspectivas que acabam sobrecarregando-os. Porém, nosso objetivo neste texto é sinalizar outra perspectiva de análise, diretamente enfocada nos benefícios que são percebidos pela docência na EaD. Esses elementos positivos estão presentes em experiências na modalidade e são destacados por profissionais que atuam na área.

Desse modo, pretendemos estabelecer uma análise que se distancia de outras que temos feito no que toca à docência na EaD. Mais especificamente, nos propomos a identificar elementos positivos que decorrem da atuação como docente na modalidade. Entendemos que a flexibilidade dos cursos a distância propicia benefícios que não são percebidos apenas pelos alunos, mas também pelas profissionais docentes. São aspectos relacionados ao caráter inclusivo que parece não se dissociar da EaD. Sendo assim, encontram-se, a seguir, os aspectos metodológicos que situam as nossas análises a partir de dados coletados com docentes que atuam ou já atuaram no âmbito do Sistema UAB. Posteriormente, enfocamos alguns resultados, sobretudo qualitativos, de questionários e entrevistas que nos dão indícios relevantes a respeito da inclusão que a EaD proporciona aos profissionais na medida em que se mostra assentada num trabalho flexível, realizado a distância e por meio das TDIC.

\section{Procedimentos metodológicos da pesquisa}

Os dados apresentados neste artigo são resultantes da pesquisa de mestrado intitulada "Organização do Trabalho Docente na Educação a Distância: implicações da polidocência no contexto da Universidade Aberta do Brasil (UAB)" de Veloso (2018). Trata-se de uma investigação realizada no âmbito do Grupo Horizonte (Grupo de Estudos e Pesquisas sobre Inovação em Educação, Tecnologias e Linguagens) da Universidade Federal de São Carlos (UFSCar). Tais considerações são importantes, pois situam nossa pesquisa à luz dos esforços maiores que têm sido 
desenvolvidos pelo Grupo Horizonte, na tentativa de desvelar os elementos que permeiam a EaD no Brasil.

No que diz respeito aos procedimentos metodológicos, optamos pela triangulação metodológica (DUARTE, 2009), ou seja, lançamos mãos de diferentes métodos numa mesma investigação. Mais especificamente, utilizamos os métodos quantitativo e qualitativo, posto que ambos podem ser utilizados lado a lado ou simultaneamente (DUARTE, 2009). Enquanto o quantitativo se preocupa com ordens de grandezas e suas relações, o qualitativo se atenta à compreensão do não quantificável (SILVA, 1998). Acreditamos que ambos os métodos são importantes, visto que nos possibilitam uma compreensão multifacetada do intricado trabalho docente que tem sido realizado na EaD.

Salientamos, ainda, que o objeto de estudo foi o Sistema UAB, de sorte que os profissionais que participaram da pesquisa são docentes que atuam ou já atuaram em cursos fomentados por essa política pública. Precisamente, foram inquiridos os docentes-autores/conteudistas, o docentes-formadores/aplicadores e os docentes-tutores virtuais e presenciais. Os dados foram obtidos por meio de questionários e entrevistas semiestruturadas.

Para a coleta dos dados, usamos o software LimeSurvey, uma ferramenta digital de código aberto (LIMESURVEY, 2017, online) que possibilita a criação de questionários virtuais. Primeiramente, foi elaborada uma lista de e-mails de profissionais que possivelmente atuam ou já atuaram no âmbito do Sistema UAB. Após isso, foram enviados convites para a pesquisa por meio do próprio LimeSurvey. No total, foram obtidas 677 respostas de docentes que possuem experiência na EaD. Destes profissionais, 8 foram convidados e aceitaram participar de entrevistas semiestruturadas, com vistas a aprofundar a coleta e, posteriormente, a análise dos dados. Concomitantemente à aplicação dos questionários e entrevistas, realizamos análises documentais, especificamente em documentos, processos seletivos, editais e outras informações disponibilizadas virtualmente pelas instituições públicas que oferecem cursos a distância. 
Reiteramos que as nossas apreciações evidenciaram diversos elementos perversos que têm permeado as experiências no âmbito do Sistema UAB. Para Belloni (2013), essa política pública economiza justamente na remuneração e na organização do trabalho docente. Justamente por isso, parece-nos que a EaD tem se utilizado de tendências da reestruturação produtiva com a finalidade de aumentar a exploração dos trabalhadores. Todavia, não obstante às perversidades nítidas em análises por nós empreendidas, bem como presentes no referencial teórica da área, identificamos que a maior parte dos profissionais gosta de atuar na modalidade. Aliás, muitos deles entendem que, não fossem as características dos cursos a distância como a disparidade geográfica, estariam impossibilitados de trabalhar ou estudar. Ou seja, acreditamos que o caráter inclusivo da EaD tem sido percebido e tem beneficiado os docentes que atuam na modalidade. Assim, o objetivo precípuo deste artigo é discutir a inclusão possibilitada pela modalidade sob a perspectiva da docência. Trata-se de um contraponto aos demais estudos que temos empreendido, colimando explorar respostas dos docentes que têm alta incidência e relevância nas coletas que foram feitas.

\section{A inclusão dos trabalhadores docentes por meio da Educação a Distância}

No questionário virtual os docentes foram indagados a respeito dos principais motivos que os levaram a atuar na EaD. Malgrado às perversidades presentes na docência exercida nessa modalidade, a maior parte dos profissionais parece gostar de atuar num curso a distância. Portanto, buscamos compreender, na visão dos docentes, quais são as aspirações e motivações que os levam a optar pelo trabalho na EaD. Os resultados desse questionamento se encontram na Figura 1. 
Figura 1 - Principais motivos que levaram os docentes a optarem pelo trabalho na $\mathrm{EaD}^{3}$.

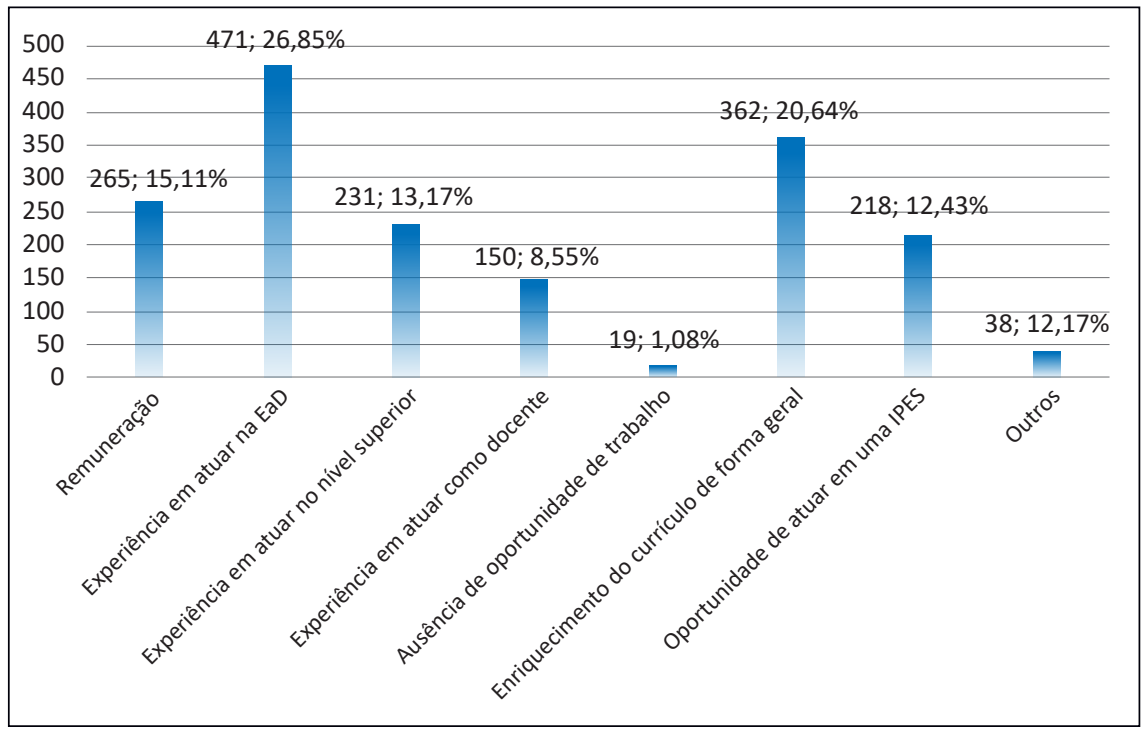

Fonte: Elaborado pelos autores.

Os dados nos mostram que as principais motivações dos docentes estão relacionadas à experiência na modalidade e ao enriquecimento do currículo. Por um lado, essas aspirações podem colocar os docentes à mercê das perversidades que subjazem à docência na EaD, sujeitando-os, inclusive, às relações de poder que têm se estabelecido no âmbito do Sistema $\mathrm{UAB}^{4}$. Por outro, esses dados nos permitem conjecturar que a modalidade tem oferecido respaldo àqueles que buscam experiência profissional. É inegável que a expansão de cursos a distância no Brasil vem acompanhada de um aumento significativo no número de profissionais engajados

${ }^{3}$ A soma das respostas não resulta em 677 , pois a questão permitia que os participantes marcassem mais de uma opção. A porcentagem foi calculada com base no total de respondentes, isto é, 677.

${ }^{4}$ Esse aspecto foi melhor discutido na dissertação de mestrado intitulada de "Organização do Trabalho Docente na Educação a Distância: implicações da polidocência no contexto da Universidade Aberta do Brasil (UAB)" de Veloso (2018). 
na modalidade, atuando no ensino superior. Em análises documentais, identificamos que o Sistema UAB apresenta exigências mais flexíveis no que toca à contratação de tutores, fazendo com que profissionais sem pós-graduação stricto sensu tenham oportunidade de atuar como docentes em cursos de graduação ou pós-graduação. Isto é, profissionais que atuam noutros níveis educacionais, como na educação básica, encontram na EaD uma oportunidade para atuar no ensino superior, conforme dito por uma tutora virtual numa das entrevistas realizadas.

Eu gosto [de atuar na EaD], porque como eu sou professora e trabalho com as crianças menores, com início da alfabetização, é uma outra realidade, quando eu tive essa oportunidade de trabalhar com alunos que eram adultos, foi muito legal, porque foi uma coisa nova pra mim. No começo, assim, era um desafio, mas depois eu percebi que foi muito tranquilo, e aquele medo, aquela insegurança eu fui... aos poucos foi, assim... fui me sentindo segura, aprendendo até sobre o curso, pra levar, mas eu senti, assim, que era uma relação que não precisava ter aquele medo, aquela... e foi uma... eu achei que é uma relação gostosa de ter, mas com adultos, né, assim, não era... porque eu sei que, assim, é diferente quando você trabalha com adolescentes, professor de ensino médio, fundamental dois, né... no caso aqui eu trabalhei com professores já, então já eram outros mesmos... então, assim, foi legal, eu gostei muito dessa relação. Por mais que às vezes eu tive alguns problemas com alguns alunos... tem sempre algumas questões, mas eu consegui contornar, consegui resolver, né... então, assim, eu gostei, foi muito bom. Por isso também que eu quis, assim, voltar, ter... continuar trabalhando nessa área, né, assim, de tutora, né (docente-tutora presencial).

A partir das considerações supramencionadas, depreende-se que a tutora encontrou na $\mathrm{EaD}$ uma oportunidade de atuar no ensino superior. Essa experiência, de acordo com a entrevistada, foi profícua à sua profissão. $\mathrm{O}$ caráter inclusivo da modalidade se estende, pois, há flexibilidade na contratação dos docentes, porque o Sistema UAB tem acolhido professores da educação básica que possivelmente noutras condições estariam à margem de experiências em cursos de graduação ou pós-graduação. 
Além disso, a atuação na EaD pode trazer elementos positivos na medida em que exige um domínio das TDIC. De acordo Cruz (2016), os estudantes relatam que, em sua grande maioria, os professores continuam apegados a uma cultura livresca baseada na leitura, discussão e memorização de materiais impressos. Para Belloni (2013), é uma evidência que os modos de aprendizagem das novas gerações são diferentes daquelas precedentes, pois a abordagem dos jovens é fundamentalmente diferentes da dos adultos. Junior (2013, p. 115) assevera que "as tecnologias são catalizadoras de mudanças e é inevitável que o seu uso necessariamente passe pela mudança de metodologias, de práticas e de uma cultura". Para o autor, a EaD intensifica esse cenário, uma vez que emprega as tecnologias como recurso de interação e de acesso ao conhecimento pelos estudantes (JUNIOR, 2013). Assim, a utilização constante das TDIC na modalidade tende a contribuir para o processo formativo dos docentes. Noutras palavras, os profissionais encontram, na $\mathrm{EaD}$, um subsídio para repensarem a própria prática a partir da utilização das tecnologias digitais em âmbito educacional. Nos questionários evidenciamos que a grande maioria dos entrevistados considera a experiência na modalidade como importante para a formação, conforme nos mostra a Figura 2. 
Figura 2 - Docentes que consideram a prática na EaD como profícua à formação profissional.

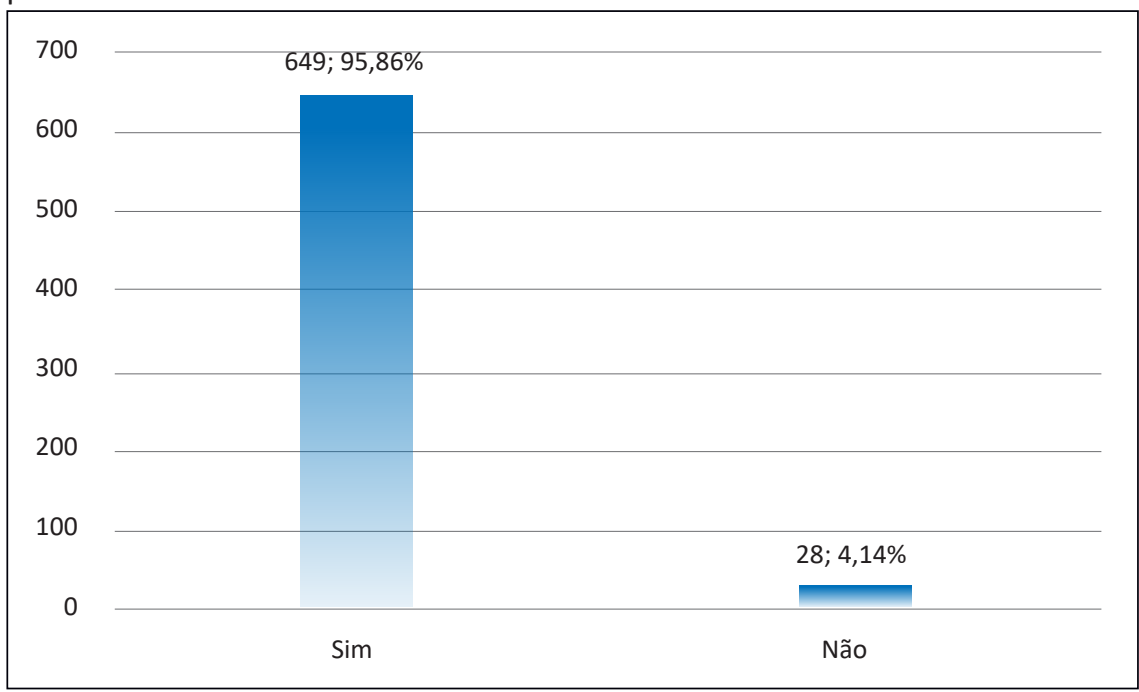

Fonte: Elaborado pelos autores.

Os docentes também foram indagados, por meio de resposta aberta, sobre o porquê da experiência na $\mathrm{EaD}$ contribuir para o processo formativo. As respostas comprovam que, para muitos profissionais, a experiência na modalidade oportuniza um olhar crítico para com a educação. Vários docentes, inclusive, afirmaram que a atuação em curso a distância proporciona melhorias na educação presencial, posto que permite validar o uso das TDIC no processo de ensino-aprendizagem.

Belloni (2013) afirma que as tecnologias digitais tanto podem funcionar como meios eficazes de opressão da liberdade, quanto como instrumentos de exercícios da cidadania. "Modos de uso criativos, críticos e inteligentes podem fazer delas ferramentas poderosas de democratização do acesso ao conhecimento e à cultura" (BELLONI, 2013, p. 247). Dessa forma, o pensamento crítico em face dos avanços tecnológicos é fundamental à utilização profícua das tecnologias, sobretudo em âmbito educacional. Se a formação docente é deficitária e as políticas públicas não 
têm dado conta de atender às demandas dos professores no que diz respeito à compreensão crítica das TDIC na educação, a EaD pode contribuir para o processo formativo dos educadores.

Percebe-se, assim, um paradoxo que perpassa as experiências na modalidade. Se, por um lado, a flexibilização no âmbito do Sistema UAB almeja contratar profissionais com menor titulação, a fim de que recebam menos por suas atividades e se sujeitem às perversidades do trabalho, por outro lado, essa experiência possibilitada pela mesma flexibilização tende a contribuir para o processo de inclusão dos docentes ${ }^{5}$. Isto é, professores da educação básica que não tiveram uma formação inicial ou continuada em consonância às novas demandas da contemporaneidade podem encontrar na EaD uma experiência formativa que, de acordo com nossos dados, configura-se como importante para a atuação profissional. A modalidade parece incluir os trabalhadores não apenas por flexibilizar as exigências dos editais de contratação, mas também por viabilizar experiências formativas que a educação presencial não tem oferecido.

Nas palavras de Fernandes e Braga (2018), as pesquisas da área devem se articular com a utilização de dispositivos tecnológicos no seio educacional e toda a gama de tecnologias móveis em sala de aula a fim de

${ }^{5}$ Esse suposto paradoxo oriundo do trabalho contemporâneo foi muito bem discutido por Kuenzer (2005). A autora assenta suas análises nos conceitos de exclusão includente e inclusão excludente. Por um lado, o mercado se utiliza de várias estratégias de exclusão do mercado formal, esfacelando direitos trabalhistas, de modo que os trabalhadores são posteriormente incluídos mediante formas precárias de contratação, como o trabalho em domicílio ou teletrabalho sem vínculo empregatício - forma de contratação recorrente no Sistema UAB. Por outro, verifica-se diferentes estratégias de inclusão nos diversos níveis e modalidades da educação escolar que não correspondem aos necessários padrões de qualidade que permitam a formação de identidades autônomas intelectual e eticamente, a fim de superar as exigências da sociedade capitalista (KUENZER, 2005). Ainda que a autora considere as duas facetas como perversas aos trabalhadores, entendemos que esse paradoxo da contemporaneidade, presente em experiências da EaD, traz elementos inclusivos que, se devidamente analisados pelos docentes, podem incorrem em benefícios, como a privilegiada experiência formativa que decorre da utilização das TDIC no seio educacional. 
promover inclusão digital. A EaD, dadas as suas especificidades, apresenta-se calcada no uso de diferentes tecnologias digitais no processo de ensino-aprendizagem. Trata-se de uma experiência privilegiada àqueles que atuam na modalidade, posto que lidam constantemente com o uso das TDIC no seio educacional. E o contato com essas tecnologias contribui tanto para o exercício da docência como para o da cidadania, porquanto os recursos tecnológicos estão cada vez mais difundidos na sociedade contemporânea.

Além do mais, o já citado teletrabalho se mostra como elemento importante no processo de inclusão dos docentes. Poder atuar em tempos e espaços flexíveis conciliando a docência com outros afazeres viabiliza a atividade laboral a diversos profissionais que estariam excluídos noutras condições. Durante a entrevista com uma docente-tutora virtual, identificamos que a flexibilidade na EaD possibilitou que ela continuasse atuando profissionalmente, conciliando os estudos com o trabalho docente, a despeito dos problemas de saúde que a acometeram.

Em 2001, quando eu ainda tava na faculdade, eu fui sequestrada e daí eu não conseguia mais sair de casa. Eu tive que... eu ia pra faculdade com meu pai ou com minha mãe, eu não conseguia mais sair sozinha de casa. E foi muito difícil terminar a faculdade desse jeito, né. Nem sempre eles podiam ir juntos, mas enfim... eu terminei. Aí depois eu queria poder fazer alguma coisa, ou ter um emprego, ou alguma coisa que eu não precisasse tanto das pessoas, que eu não dependesse de ninguém, né. Ou queria continuar estudando... e daí eu vi que tinha, na época... em 2004, que eu terminei a faculdade... então, depois disso, lá para 2007 eu já tava no Rio Grande do Sul e vi que tinha um curso do SENAC a distância, sobre a educação a distância. Eu trabalhava presencial, trabalho presencial hoje, mas não é algo assim que eu goste muito, eu não gosto de ter que sair de casa, de ter que pegar o carro. Então é muito ligado, assim, ao estresse pós-traumático, né. Então eu queria ter o direito... e quando eu fiz o curso de EaD, no SENAC, sobre educação a distância, eu percebi que não só casos como o meu, mas por exemplo, se você tá no hospital, há 6 meses, você não ter o direito de estudar, ou então se você mora lá na aldeia indígena, que não tem faculdade próxima, você não tem o direito de estudar como os outros? Então eu fui percebendo que tinha vários motivos para existir a Educação a Distância. Hoje eu já tô bem 
melhor, já saio de casa, já dou aula de canto fora de casa, mestrado. Mas eu continuo gostando muito da Educação a Distância, por causa desse fator inclusão, porque inclui muito mais pessoas (docente-tutora virtual).

A fala da docente é bastante enfática ao mencionar o fator inclusivo da $\mathrm{EaD}$ como uma de suas características fundantes. Há que se destacar que, em países de dimensões continentais e de acentuada desigualdade social como o Brasil, são necessárias estratégias que permitam a democratização e a interiorização do acesso à formação, sobretudo superior. Nesse sentido, parece-nos que a EaD está alinhada às demandas decorrentes da contemporaneidade. Em nossa pesquisa, verificamos que a inclusão se dá também na perspectiva docente, considerando-se que as experiências no âmbito do Sistema UAB têm oferecido oportunidades a diferentes perfis de profissionais. Atentamo-nos às questões perversas que subjazem ao trabalho flexível, mas não podemos desconsiderar que elementos positivos foram relatados pelos profissionais e estiveram presentes nos resultados da investigação. Elementos estes que se relacionam, dentre outras coisas, à inclusão que a EaD proporciona, tendo em vista que a flexibilidade permite que os trabalhadores conciliem suas atividades laborais com outras demandas. Além disso, as características da docência na modalidade fazem com que os profissionais consigam sobrepujar diferentes óbices, como aqueles relacionados às dificuldades geográficas, aos problemas de saúde, ao descaso do Estado, às situações de opressão etc.

\section{Considerações finais}

Dentre os principais objetivos do Sistema UAB destacam-se a expansão e a interiorização da oferta da educação superior pública. Em países de grande extensão territorial e acentuada desigualdade social como o Brasil, a EaD ganha destaque, oferecendo formação àqueles que, noutras condições, não seriam atendidos. Percebe-se, assim, o caráter inclusivo da modalidade. No entanto, há um enfoque na perspectiva dos discentes, uma vez que os cursos a distância possibilitam que diferentes 
segmentos populacionais tenham acesso à educação. Parece-nos que, tão importante quanto a inclusão propiciada aos alunos é aquela que beneficia os docentes que atuam na EaD.

Nesse sentido, este texto traz alguns dados de docentes que atuam ou já atuaram no âmbito do Sistema UAB, propondo uma discussão diretamente enfocada no caráter inclusivo da modalidade. Acreditamos que a flexibilidade da $\mathrm{EaD}$, para além dos elementos perversos inerentes ao trabalho contemporâneo, oferece oportunidade a professores e profissionais da educação. Em nossas análises, verificamos que, por praxe, a função de tutoria é exercida por docentes que atuam na educação básica, sendo que a $\mathrm{EaD}$ permite que eles tenham experiência no ensino superior. Ademais, sabemos que, via de regra, a formação de professores no Brasil ainda não tem dado conta das demandas decorrentes dos constantes avanços das TDIC. Desse modo, a EaD fornece, muitas vezes, uma experiência privilegiada para os profissionais, porquanto utiliza constantemente das tecnologias no processo de ensino-aprendizagem.

Nossa pesquisa também trouxe dados relevantes a respeito do caráter inclusivo proporcionado pela docência virtual. Uma docente-tutora entrevistada disse que, em decorrência de problemas de saúde, a $\mathrm{EaD}$ se constituiu como principal oportunidade para voltar ao trabalho e aos estudos. Na visão dela, a modalidade pode oferecer acesso à educação a diferentes parcelas da sociedade que não são atendidas pelo ensino presencial. De fato, a literatura da área discute as potencialidades da EaD no que concerne à democratização do acesso educacional.

Posto isso, reiteramos que nossa intenção, neste artigo, não é propor a modalidade como uma espécie de panaceia à desigualdade social e aos problemas que permeiam o País. Pelo contrário, entendemos que a flexibilização do trabalho contemporâneo está imbuída de intenções perversas, objetivando aumentar a exploração dos trabalhadores. Conforme afirmado neste texto, temos discutido os aspectos negativos da docência na EaD a partir dos dados coletados em nossa investigação. No entanto, a coleta de dados também nos trouxe informações que evidenciam outra 
faceta da modalidade, relacionada ao caráter inclusivo proporcionado pela flexibilidade temporal e espacial dos cursos a distância. Assim, neste artigo, propusemo-nos a analisar esses elementos positivos relatados pelos docentes, contrapondo-nos a outras análises que temos empreendido no que toca à docência exercida na EaD.

\section{Referências}

BELLONI, M. L. Mídia-educação e educação a distância na formação de professores. In: MILL, D.; PIMENTEL, N. (Org.). Educação a Distância: desafios contemporâneos. São Carlos: EdUFSCar, 2013. p. 245-265.

CRUZ, D. M. Letramentos, práticas pedagógicas e formação de professores para as mídias: reflexões sobre a relação entre a cultura digital e a universidade. In: MILL, D.; REALI, A. (Orgs.). Educação a Distância, Qualidade e Convergências: sujeitos, conhecimentos, práticas e tecnologias. São Carlos: EdUFSCar, 2016. p. 177-192.

DUARTE, T. A possibilidade de investigação a três: reflexões sobre a triangulação (metodológica). CIES e-WorkingPaper, Lisboa, n. 60, p. 1-24, 2009.

FERNANDES, J. R.; BRAGA, F. M. Inclusão digital. In: MILL, D. (Org.). Dicionário crítico de educação e tecnologias e de educação a distância. São Paulo: Papirus, 2018. p. 333-336.

FERREIRA, M.; CARNEIRO, T. C. J. A institucionalização da educação a distância no ensino superior público brasileiro: análise do Sistema Universidade Aberta do Brasil. Educação Unisinos, São Leopoldo, v. 19, n. 2, p. 228-242, maio-jun. 2015.

JUNIOR, K. S. A institucionalização da educação a distância no Brasil: cenários e perspectivas. Teoria e Prática da Educação, São Paulo, v. 11, n. 1, p. 113-124, jan.-abr. 2013. Disponível em: <http://periodicos.uem.br/ojs/index.php/ TeorPratEduc/article/view/23767>. Acesso em: 15 ago. 2017. 
KUENZER, A. Z. Exclusão includente e inclusão excludente: a nova forma de dualidade estrutural que objetiva as novas relações entre educação e trabalho. In: SAVIANI, D.; SANFELICE, J. L.; LOMBARDI, J. C. (Org.). Capitalismo, trabalho e educação. 3. ed. Campinas: Autores Associados, 2005.

LIMESURVEY. Limesurvey: the online survey tool - open source surveys. 2017. Disponível em: <https://www.limesurvey.org/>. Acesso em: 16 nov. 2017.

MILL, D. Gestão estratégica da educação a distância: constituição, complexidades e desafios. In: NEVES, I. de S. V.; CORRADI, W.; CASTRO, C. L. F. de (Org.). EaD: diálogos, compartilhamentos, práticas e saberes. Barbacena: Eduemg, 2016. p. 129-144.

MOORE, M.; KEARSLEY, G. Educação a distância: uma visão integrada. Trad. Robert Galman. 2. ed. São Paulo: Thomson, 2007. 398 p.

NEVES, I. de S. V. Diálogos sobre EaD e práticas pedagógicas. In: NEVES, I. de S. V.; CORRADI, W.; CASTRO, C. L. F. (Org.). EaD: diálogos, compartilhamentos, práticas e saberes. Barbacena: Eduemg, 2016. p. 15-24.

SANCHO-GIL, J. M. A aprendizagem, o conhecimento e a relação pedagógica: implicações para o ensino tradicional e a distância. In: MILL, D.; REALI, A. (Org.). Educação a Distância qualidade e convergências: sujeitos, conhecimentos, práticas e tecnologias. São Carlos: EdUFSCar, 2016. p. 161-175.

SILVA, R. C. A falsa dicotomia qualitativo-quantitativo: paradigmas que informam nossas práticas de pesquisa. In: ROMANELLI, G.; BIASOLI-ALVES, Z. M. M. (Org.). Diálogos metodológicos sobre prática de pesquisa. Ribeirão Preto: Legis Summa, 1998. p. 159-174.

VELOSO, B. Organização do trabalho docente na Educação a Distância: implicações da polidocência no contexto da Universidade Aberta do Brasil (UAB). 2018. 214 p. Dissertação (Mestrado em Educação) - Centro de Educação e Ciências Humanas, Universidade Federal de São Carlos, São Paulo, 2018. Disponível em: <https://repositorio.ufscar.br/bitstream/handle/ufscar/9742/VELOSO_\%20 Braian_2018.pdf?sequence=7\&isAllowed $=y>$. Acesso em: 28 jul. 2018. 
VELOSO, B.; MILL, D. Precarização do trabalho docente na educação a distância: elementos para pensar a valorização da docência virtual. Educação em Foco, Juiz de Fora, v. 23, n. 1, p. 111-131, jan. 2018. Disponível em: <https://educacaoemfoco. uff.emnuvens.com.br/edufoco/article/view/3344>. Acesso em: 28 jul. 2018.

VELOSO, B.; MILL, D. Teletrabalho docente na educação a distância: sobrecarga nas atividades dos trabalhadores. In: Encontro Brasileiro da Rede Latino-Americana de Estudos sobre o Trabalho Docente, 9. 2017, Universidade Estadual de Campinas. Anais... Campinas: REDESTRADO, 2017. p. 1-14. Disponível em: <http://anaisbr2017.redeestrado.org/files/abstracts/000/000/084/original/ Braian_Veloso_Daniel_Mill.pdf $>$. Acesso em: 28 jul. 2018.

Recebido: 30/07/2018

Received: 07/30/2018

Recibido: 30/07/2018

Aprovado: 01/02/2019

Approved: 02/01/2019

Aprobado: 01/02/2019 